\title{
Influence of Exogenous and Anthropogenic Impacts on Natural Ecosystems in Azerbaijan
}

\author{
Rae ZH Aliyev* and GSh Mamedov \\ Institute of Soil Science and Agro chemistry of NAS of Azerbaijan, Azerbaijan
}

Received: 阱 March 23, 2018; Published: 畊 April 06, 2018

*Corresponding author: Rae ZH Aliyev, Institute of Soil Science and Agro chemistry of NAS of Azerbaijan, Azerbaijan

\begin{abstract}
Located in the South Caucasus Republic of Azerbaijan-mountainous country where $60 \%$ of its territory is mountainous and foothill zone. Difficult geographical situation of mountain systems, the constantly increasing anthropogenic forcing exogenous processes occurring in the country, non-compliance with conservation and environmental protection measures eventually led to the emergence and development of erosion processes. The article discusses ways of ecological optimization of agricultural land in the country.
\end{abstract}

Keywords: Resource; Agrolantshtaft; Biosphere; Vodohrannoe; Optimization

\section{Introduction}

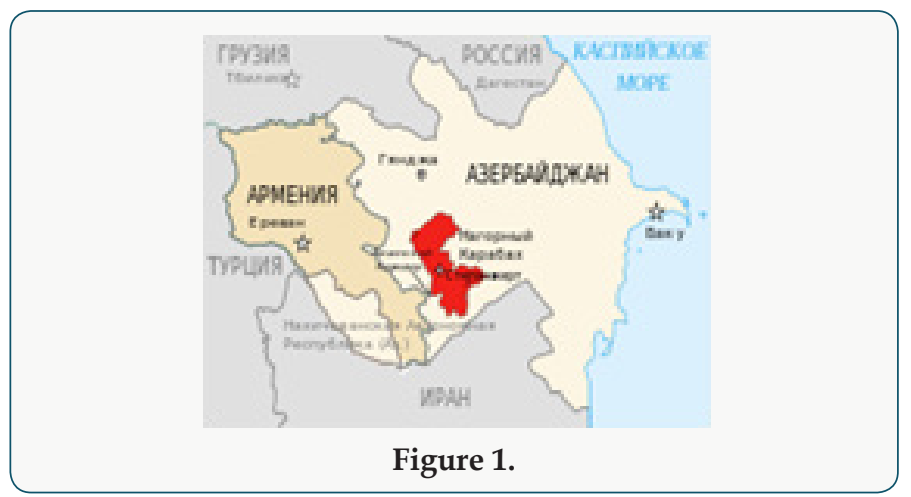

(Figure 1) Nature within Azerbaijan Republic allocated mountains and Plains landscapes, including a number of classes of types. Intense and often not rational use of mountain lands, including lands involving forests in agriculture leads to a reduction in arrays of mountain forests of great vodohrannoe and conservation value; water pollution, intensive development of erosive processes, change and change the appearance of individual components of nature, reduce the biological resources of the biosphere, contribute to the destruction of the balance of natural ecosystems. You should take care about keeping as many diverse protected places on the territory of the Republic of biovidovym-rich variety that could be a source for recovering species in the succession community's ranks. Exploitation of valuable to mankind natural systems should not exceed their ability to heal itself. In the course of successions (inheritance succession) formed gradually more stable combination corresponding to abiotic conditions Wednesday, increasing species diversity, complicated relationship between bio organizmami and increasing regulatory opportunities within ecosystems. While manmade violations do not exceed samovosstanavli in capacity arising from the change of demutacionnye conversion may return to its original state qualification. This happens when the sanitary felling of forest zones. But if the strength and frequency of the effects go beyond these capabilities initially resistant, rich in species community gradually degenerates, followed by a small ability to samovozobnovleniju.

\section{The Purpose of the Study}

With environmental positions dangerous simplify human natural environment. On the territory of the Republic, where man-made landscapes have received and receive sufficiently wide development and distribution of biotic Wednesday should be rich in species diversity of vegetation in the Park, recreational areas, water bodies, in the seaside Strip. Agricultural landscapes must be diverse with wild stripes around the fields, and in the zone of wind erosion with hedges and copses. Such problems in 
the Republic, as undermining the natural fertility, as a result of a breach of the processes of formation of humus, pollution, pesticide Wednesday organic waste, soil erosion, etc. caused by weakening of regulatory capacity soils [1-5]. Ecosystem stability, reliability, leakage of biokrugovorota substances based on species diversity and fullness of the successions resulting from the transformation of communities on the basis of the long-term evolution of species.

Researchfacility is alarge mountainouszone, the LesserCaucasus and the Nakhichevan Autonomous Republic. Modern human society is developing at the beginning of a new era of the third millennium a period of rapid technological advances, space exploration, and the development of genetic engineering, information and Nano technology. At the present stage of development of human society is expanding production and productive human activity, intensively exploited natural resources, expanding exploration underground storerooms, constantly increase seeding the square, accompanied by the destruction of forests and pastures. All this helps to limit the adaptation of living organisms in Wednesday, as modified by anthropogenic influence. In the new environment, humankind is obliged along with maintaining constant natural landscape, to promote environmental management in conditions of global technology advances.

\section{Objectives of research}

Studying of exogenous and anthropogenic impacts on the natural landscape of the Republic of Azerbaijan.

One of the main parts of this problem-determination of the permissible limits of nature management, guaranteeing the preservation of landscapes and economic balance of the entire biosphere in time. This is the need for a comprehensive study of exogenous and anthropogenic impacts on natural landscapes. It should be noted that the soil is a vital part of the biosphere, and one of the specific components of the landscape and is formed under the influence of biocoenoses, successive, at the same time it acquires the structural and functional properties, which may persist indefinitely and, in turn, affect change biocoenoses. In the second half of the last century began to take shape a new economic concept of awareness of land as many functional element of the natural landscape.

\section{Strokes: study}

In mountainous and Foothill regions erosive process-one of the main causes of damage to soils. Destruction of soils from erosion processes manifests itself in various forms and covers a huge area on the globe. The most important contemporary problem of soil science, biology, geophysics, agronomic and other sciences close to them, is the study and evaluation of biological resources, as well as the rationale for their enhancement and management. People and its economic activity is one of the components of the ecosystem of the globe, and its connection with the now more complicated. The man and his work is closely linked with the biosphere and its system: organisms-soil in connection with these business activities (deforestation, cultivation of land, forests and terraces etc.) of a person directly affected the biosphere. Generally deforestation, water, wind, Gramma, irrigation and erosion of many other phenomena, as well as exogenous processes are reshaping certain regions of the biosphere. In mountainous areas, the destruction of forests and forest litter caused in hydrology of mountain rivers and water regime of the soil such significant changes that affect the water regime of the rivers lowland, turbidity and salinity in rivers, reservoirs, zailenii the status of fisheries and energy resources. We were tasked to examine ecological optimization of agro-mining zone. It should be noted that the study of these processes in the mountain zone requires a systemic approach. System landscapeecological approach in the mountainous areas of the Republic provides for conjugate study and rehabilitation of eroded lands, degraded and factors influencing these processes in a unified composition of ecosystems.

The main task of the theoretical basis and this approach is the study of the processes of organic substances, material and energy exchange between the ecosystem components and the soil. In this connection, it is advisable, first of all to develop a micro approach to specific structural and functional elements of the soil system (mineral part living substance and dead organic matter) on the basis of which explores their functioning as in natural conditions, and ditching environmental pressure (reclamation). Here it is pertinent to note that the micro approach is the methodological installation, which will allow us to solve tasks in view. Optimizing natural among in the Azerbaijani Republic has the task of seeking a balanced relationship between the exploitation of Geosystems (rational use of natural resources), their security and effectively targeted using. At the same time this set of measures is aimed at ensuring the mineral conditions necessary for the preservation, restoration and education key components of the landscape. The basic approach and scientific substantiation for the development of a set of measures to ensure the stability of the landscape is landscape ecology, which studies the structure and functioning of ecosystems in specific landscape settings, as well as an assessment of the interaction of parts, natural complex and anthropogenic impacts by analyzing balance sheets of matter and energy. It is necessary to take into account the complexity and systematization of the relationship between natural components of landscape and anthropogenic effects. It should be noted that due to these properties, protection and management of any individual component natural Wednesday has no real meaning outside of the more complex optimization of integrated units.

In terms of the land reform carried out in the Republic, the emergence of krestjansko farms, a deepening of the market relations requires optimization of agro. One of the important ways of optimizing, use of agro-landscape is improving agricultural production, implementing best practices and new research obtained in the advanced countries, in compliance with the characteristics 
national traditions and the ancient culture of the agriculture Republic. In the Republic of Azerbaijan, where mountain ranges occupy more than half of the territory and the soil cover was formed in accordance with the law of vertical zonation, with complexes of the mountain-meadow, mountain forest, steppe and semidesert, an important foundation planning for optimization, are nature-territorial complexes within the zonal landscapes, diverse natural conditions and the degree of anthropogenic development, as well as land structure and functional the appointment [3.4] Mountain landscapes of the Republic are characterized by variety of morphometric terrain, availability of sufficient amount of moisture and chemical composition. The formation of these soils and their functioning in landscape-genetic conditions are primarily determined by the availability of zillion moisture and chemicals compounds, offal and watershed mountains Alpine and subalpine zones. A distinctive feature of the mountain soil formation is that the slopes soils are formed in different bioclimatic and orogeomorfologicheskih conditions. Depending on the thermal, bioclimatic and orogeomorfologicheskih conditions, exposure to soil erosive processes, weathering and pedogenesis pierced with varying degrees of intensity, that contributes to provincial characteristics of soil vertical zoning system.

A distinctive feature of the mountainous zone is that here is quite high radiation balance, but the duration of vegetation period is significantly less than on the Plains. The totality of these circumstances contributes to slowing down the process of decomposition of plant opadi and forming dernavoi horizon. In such circumstances, the plant remains fully mineralize, resulting in significant accumulation of coarse humus with fulvatnym and gumatno-fulfatnym compound [2,6]. It should be noted that the evaluation and selection of sites of intense withdrawal and the accumulation of chemicals in the landscape is only possible when studying geochemical compatibility of natural and anthropogenic chemicals flow. In order to develop principles of optimization should be consideration of the landscapes of natural and anthropogenic processes dynamics. This task meets the idea of natural regimes as an integral feature of Geosystems, it should be noted that in this zone, reliable data transfers moisture and chemicals and natural modes, sex-related when examining these processes at the test sites-hospitals, integrated method transeptah ordination developed by Siberian researchers. Practiced also the study of matter and energy flows. In the Alpine zone under the influence of the denudacionnyh processes going on mechanical and geochemical takeaway pereotlozhenie substances and mineral soil mass and the deformation of the soil cover. Thus the mozoika soil of mountain systems is a reflection of the natural environment, particularly the relief of historically in this natural area. For the development of activities relating to the management of natural and human-induced processes that require specific knowledge of their intensity and dynamics, particularity, study intensity all types of erosion processes, overcrowding, and downgrading biological activity of soil eutrophication of reservoirs.
There is also a need to assess natural and anthropogenic factors contributing to strengthening these processes. In this regard, recognize that not one natural system does not have absolute resistance to tehnogenezu $[3,5]$ therefore very relevant is the assessment of individual properties retain the original components (soil, biota, water). In connection with this highly relevant is to assess trends in geochemical activity Wednesday, as the most important indicator for predicting possible its self-cleaning $[3,4,6]$. It should be noted that a State of equilibrium is achieved by Geo systems optimizations circulation of substances and flow into them while managing the process spans bio geocenoticheskogo stabilization mechanism in soils. B.g. Aliyev noted: "soil as a dynamic system determines the reliability and duration of the operation of the sites" [4]. Many numerical investigations conducted during the years of Soviet power in the CIS and abroad show that sustainability of Geo systems and landscapes to human impacts depends largely on the degree of sustainability of arable soil to the effects mineral and organic substances of anthropogenic origin. Products, erosion of chemicalization of agriculture, animal husbandry, water, contribute to eutrophication, siltation of occlusion of rivers, lakes and reservoirs. Is essential to achieving economic stability in agro land shafted [3-8].

\section{Discussion of the Results Obtained}

Multi-year large-scale soil erosion studies have shown that the lack of soil on the slopes of the event, the absence of machinery pochvozashhitnoj agro land shafted contributed to the leach ate may run off and erosion, destruction of soils; development of Planar, linear, wind, pasture and irrigation erosion and decline in fertility in the final total soil degradation. According to the 1990 year $41.8 \%$ of the territory of the Republic in some way or another affected by erosion. Erosive process has contributed to the destruction of natural ecosystems and inflicted enormous damage on the surrounding man Wednesday. Maintaining the ecological stability of agro vegetation plays a significant role, and the primary role of forest vegetation, which is the guarantor and natural erosion against ameliorant water regulator regime for tillage $[4,6,7]$. The intensity of forest phytocenosises of main factors on the ecological stability is determined not only by the typological and morphological traits of these communities, but also their fit omassoj and characteristics of energy its spatial properties.

Issue ecological stabilization of agro-landscape due to reduced natural habitats of plants in this area is of great importance. You must respect the principle of polarization in the zone of agrolandscape and protected areas should be removed from each other. In compliance with this principle, the conditions for the formation of most practical models agro land shafting bio geo cenoticheskogo development trend forecasting process. Experimental study conducted by scientists of Azerbaijan, have shown that the more the agro land shafted retained the natural plants the greater ecological stability and productivity, he possesses $[2,6,8]$. In connection with land reform since 2002 year and while krestjansko 
farms in conditions of intensive land use particularly vulnerable border contact between different ecosystems, territories of planted different cultures $[5,6,7]$. Here there is a maximum contrast of microclimate environment and course and water regime.

\section{Conclusion}

a) In a new context where anthropogenic load intensively increase from year to year, humanity is obliged along with maintaining constant natural landscape, to promote environmental management in conditions of global technical development progress.

b) You must set legal limits of nature management, guaranteeing the preservation of the ecological balance and the entire biosphere.

c) You must select a possible strategy aimed at recognition of ecological civilization, as one of the foundations of contemporary and future development of society.

d) Develop and implement throughout in regardless of the forms of land management priodoohrannoj technology, taking into account their zoning for the progressive saving of environmentally sound irrigation systems in the Republic of selhozproizvodstv.

\section{References}

1. Aliyev GA. Soil the Greater Caucasus (within the Azerbaijan SSR). IZD-vo “Elm", Part 1, pp. 1,978,167.

2. Aliyev BH (2000) Problems of Geology and Hydrogeology of Apsheron Baku.

3. BH Aliev, Aliev ZH (2003) Irrigated agriculture in the mountain and foothill regions of Azerbaijan. Monograph Publishing house Naji Zia EPG Ltd Baku, Azerbaijan, pp. 330

4. Aliev BH, Aliev ZH (1999) Techniques and technology few intensive irrigations in condition of the mountain region of Azerbaijan. Publishers Elm, Baku, Azerbaijan, pp. 220.

5. GSh Mamedov (2003) Ecological model of pasture fertility Adzhinourskoj steppe. Baku Elm with 74.

6. GSh Mamedov (2002) Evaluation of the soils of the North-East agricultural zone. Baku Its with 227

7. GSh (2002) Mamedov. Land reform in Azerbaijan: legal, scientific and environmental issues. Baku Ed Elm.

8. SZ Mamedova (2006) Ecological assessment and monitoring of the soils in the Lankaran region of Azerbaijan. Baku, Azerbaijan, pp. 372.

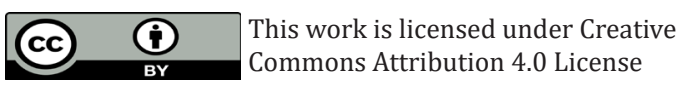

To Submit Your Article Click Here: $\quad$ Submit Article

DOI: 10.32474/CIACR.2018.01.000124

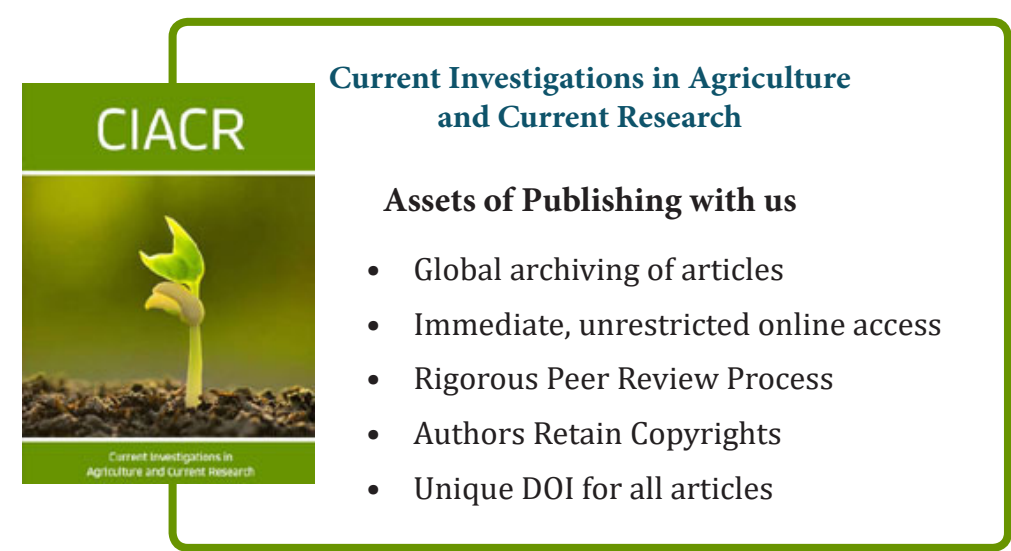

